\title{
GEOPHYSICAL MAPPING OF KIMBERLITE PIPES IN SOUTH INDIA
}

\author{
Saurabh K. Verma ${ }^{1}$ \\ ${ }^{1}$ National Geophysical Research Institute, Uppal Road, Hyderabad 500 007, India
}

\section{GEOLOGY}

Dharwar Craton, south India, has 3 distinct kimberlite fields and at least one major lamproite field - all of them located around the Cuddapah Basin (CB). The kimberlite clusters occur west of $\mathrm{CB}$, somewhat towards the center of the craton, in: 1) Wajrakarur Kimberlite Field (WKF, with 21 pipes), 2) Narayanpet Kimberlite Field (NKF, with 31 pipes), and 3) recently discovered Raichur Kimberlite Field (RKF, with 6 pipes). As a result of the intensive work carried out by the Geological Survey of India during the past couple of years, the Jaggayyapeta Lamproite Field (with more than 25 lamproitic dykes) has been established along the northwestern margin of $\mathrm{CB}$, close to the Proterozoic Eastern Ghats Mobile Belt.

\section{FACTORS CONTROLLING GEOPHYSICAL RESPONSE}

The most common geophysical methods employed in the exploration for K/L's are Gravity, magnetic, electrical, and electromagnetic surveys. These methods measure contrasts in density, susceptibility, and resistivity parameters. The kimberlites and lamproites (K/L's) in south India occur in different geological settings and depending on the contrasts in physical properties with the host-rocks, they yield different types of geophysical signatures (Verma, 2000). Being ultramafic in nature, $\mathrm{K} / \mathrm{L}$ 's are generally good magnetic targets. Hard, compact and unweathered kimberlites provide high magnetic, resistivity, and density contrasts. However, weathering changes this picture completely (Table 1) as it gives rise to conducting clayey minerals like montmorillonite and reduces the susceptibility and density of the top part of a kimberlite. Thus the success of a particular geophysical method strongly depends on the degree of weathering and the geological setting in which the pipe occurs.

In majority of the cases it is found that lamproites have much smaller dimensions (sometimes the width of a dyke could be about a meter or even less) compared to kimberlites. Thus their response is relatively more subtle and geophysical delineation more challenging.
Table 1: General geophysical property contrasts with the country rock for weathered and unweathered K/L's

$\begin{array}{lccc}\begin{array}{l}\text { K/L'S } \\ \text { Weathered }\end{array} & \begin{array}{c}\text { DENSITY } \\ \text { LOW }\end{array} & \begin{array}{c}\text { SUSCEPTIBILITY } \\ \text { LOW }\end{array} & \begin{array}{c}\text { RESISTIVITY } \\ \text { LOW }\end{array} \\ \begin{array}{l}\text { \& Altered } \\ \text { Hard \& } \\ \text { Compact }\end{array} & \text { HIGH } & \text { HIGH } & \text { HIGH } \\ & & & \end{array}$

\section{Optimum Parameters for Ground Surveys}

The K/L's in the region occur as intrusive pipes, dykes, or sills with dimensions of a few 10's to a few 100's of meters (the largest kimberlite pipe is about $900 \times 900$ $\mathrm{m}$, at Anumpalle). Outcrops of some of the kimberlite diatremes could be of very limited spatial extent (few 10 's of meter) at least in one dimension. In such situations, selection of appropriate station interval is important. A typical example is the outcrop of Pipe 7 (Venkatampalle, Anantpur Dist.) that extends to about $1400 \mathrm{~m}$ in length comprising an ensemble of lenticular bodies whose width varies from near zero to about $30 \mathrm{~m}$ (Guptasarma et. al, 2000). Thus, if a station interval of $25 \mathrm{~m}$ is chosen, the response of the pipe may not reflect in the ground magnetic survey. Similarly, if the pipe was buried (unexposed at the surface), it could be missed even when spacing between profiles was $50 \mathrm{~m}$ but they happened to be parallel to the strike of the body. Expected orientation of the $\mathrm{K} / \mathrm{L}$ body and minimum size of targets to be located provide vital clues in the selection of survey parameters.

Quite frequently deep fracture zones or dykes, etc. are associated with $\mathrm{K} / \mathrm{L}$ bodies. These linear features can have strong magnetic signatures dominating a much smaller response from a K/L. In such situations, an improper selection of the scale to plot the magnetic anomaly on a profile, or the contour interval to show the distribution of magnetic field over a region, may result in missing a $\mathrm{K} / \mathrm{L}$ target.

\section{AEROMAGNETIC SURVEYS}

Aeromagnetic surveys record the magnetic field at increased distance from the source as the height of the survey platform (fixed wing plane or helicopter) adds to 


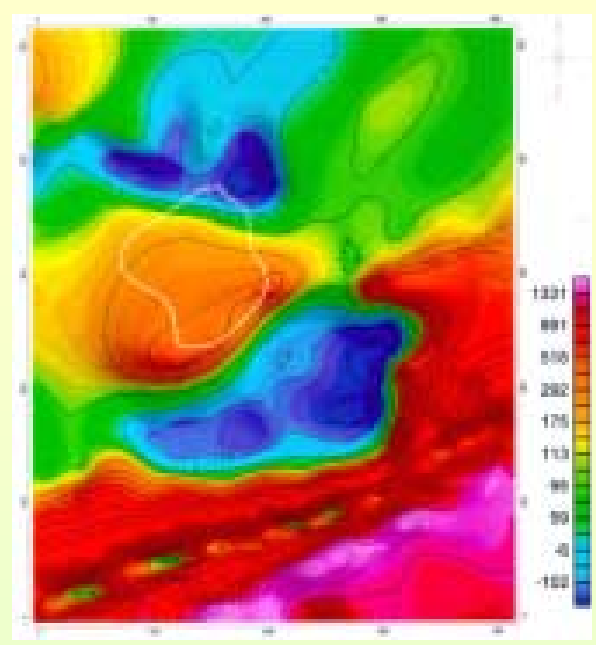

a) Ground Survey

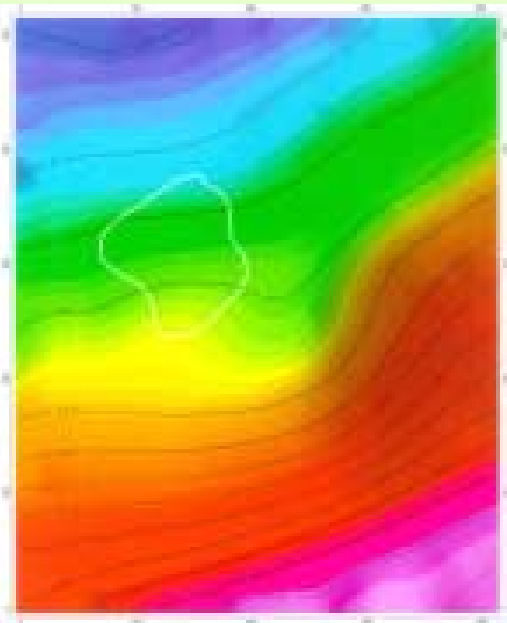

c) Height $60 \mathrm{~m}$

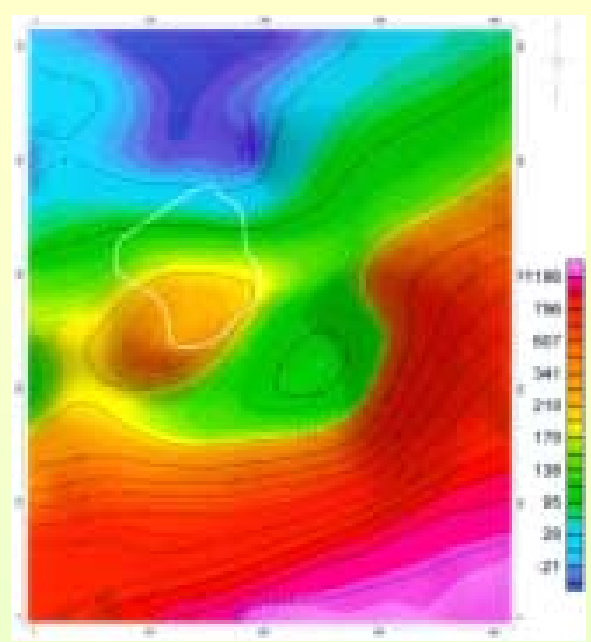

b) Height $30 \mathrm{~m}$

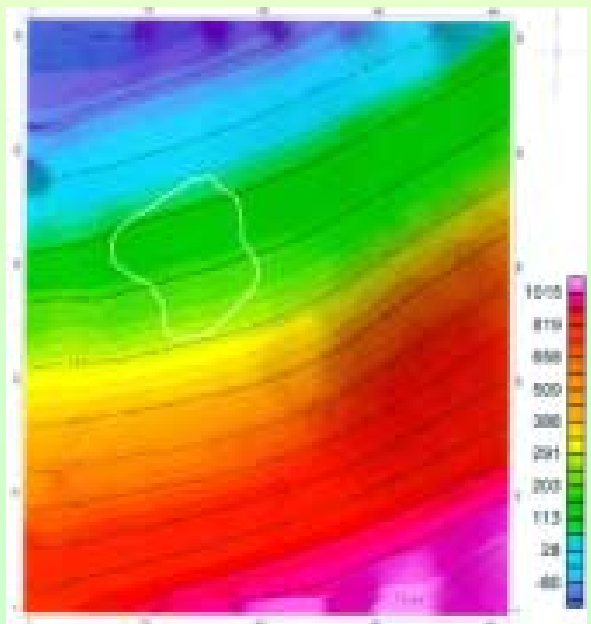

d) Height $120 \mathrm{~m}$

Figure 1: Reduction in anomaly amplitude with altitude in aeromagnetic surveys.

the overall distance from the target body. Most of the $\mathrm{K} / \mathrm{L}$ bodies are of limited dimensions and in general produce magnetic fields of dipolar nature. Magnitude of such fields varies as inverse cube of the distance. Thus in aeromagnetic surveys, the responses are significantly reduced in comparison to those obtained in ground surveys. This is shown in Figure 1 where, for the purpose of illustration, the response of a typical kimberlite (Pipe 6, Wajrakarur, AP) is collaged with the response of a strongly magnetic (susceptibility $4800 \mathrm{x}$
$10^{-6}$ cgs units) dyke similar to one associated with Pipe 7. Residual magnetic response of this kimberlitedolerite dyke system is shown in Figure 1, for a profile separation of $50 \mathrm{~m}$, at ground level (a), and at heights

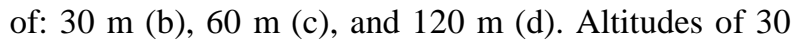
and $60 \mathrm{~m}$ were chosen as they represent heights at which helicopter-borne magnetic surveys are normally carried out. Altitude $120 \mathrm{~m}$ represents the normal height corresponding to the fixed wing surveys. Outline of the kimberlite pipe is shown in white line in all the figures. 


\section{ELECTROMAGNETIC EXPLORATION}

For weathered kimberlites, EM exploration is particularly useful in delineating the top conducting part of the pipe. General experience is that timedomain electromagnetic (TDEM) responses are less noisy compared to those obtained by frequencydomain (FDEM) measurements. Examples comparing the TDEM and FDEM responses of Pipe 6, Wajrakarur, AP, are presented to illustrate this point (Figures $2 \mathrm{a}$ and $2 \mathrm{~b}$ ). FDEM data (Figure 2a) for highest frequency $(3,555 \mathrm{~Hz})$ is affected by heterogeneities in the overburden while the lowest frequency $(222 \mathrm{~Hz})$ does not see the pipe very clearly. This is clearly established by the 3-D modeling of the FDEM data. Nevertheless, FDEM data for intermediate frequencies provide useful information on the size of the conductive top region. The TDEM response (Figure 2b) even for Channel 5 $(1.45 \mathrm{msec})$ records the response of the pipe clearly. In order to evaluate the depth-wise capability of FDEM and TDEM data in delineating the pipe, penetration depths for the two systems are calculated for a pipe resistivity of $5 \mathrm{Ohm} . \mathrm{m}$. This value is taken because the geophysical surveys (Kailasam et. al, 1978) indicate that the resistivity over the pipe drops steeply from a regional value of about $60 \mathrm{Ohm} . \mathrm{m}$ to less than $10 \mathrm{Ohm} . \mathrm{m}$.

Though the actual penetration depth varies depending on the real resistivity distribution inside the earth, for the sake of illustration an average effective resistivity of $5.0 \mathrm{Ohm} . \mathrm{m}$ for the pipe is considered. For this value of resistivity it is found that the FDEM measurements at the lowest frequency of $222 \mathrm{~Hz}$ penetrate up to a depth about $75 \mathrm{~m}$. In comparison, TDEM measurements at time $1.45 \mathrm{~m} \mathrm{sec}$ (channel5) correspond to a depth of about $110 \mathrm{~m}$. The 3-D images of the kimberlite pipe prepared for these maximum penetrations (with good $\mathrm{S} / \mathrm{N}$ ratio) for the two systems are shown in Figures $3 \mathrm{a}$ and $3 \mathrm{~b}$. It can be seen that the MAXMIN II (FDEM) data at a Though the actual penetration depth varies depth of $75 \mathrm{~m}$ provides a rather noisy picture of the pipe while the CPEM (TDEM) data yields a well-defined image of the pipe even at a greater depth of $110 \mathrm{~m}$. The same conclusion can be drawn from the vectors (Figure 4) obtained for the two data sets. It can be seen that the vectors are scattered in different regions for the FDEM data whereas for the TDEM data large amplitude vectors are mostly confined within the pipe.
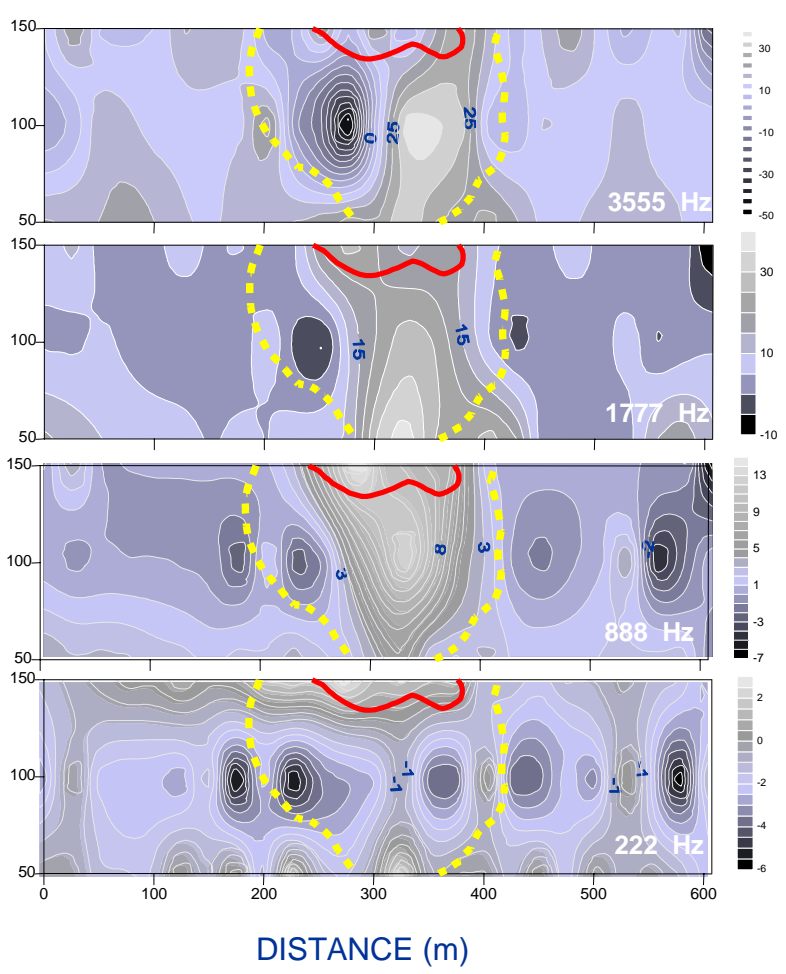

Figure 2a: FDEM response of Pipe 6, Wajrakarur, A.P.

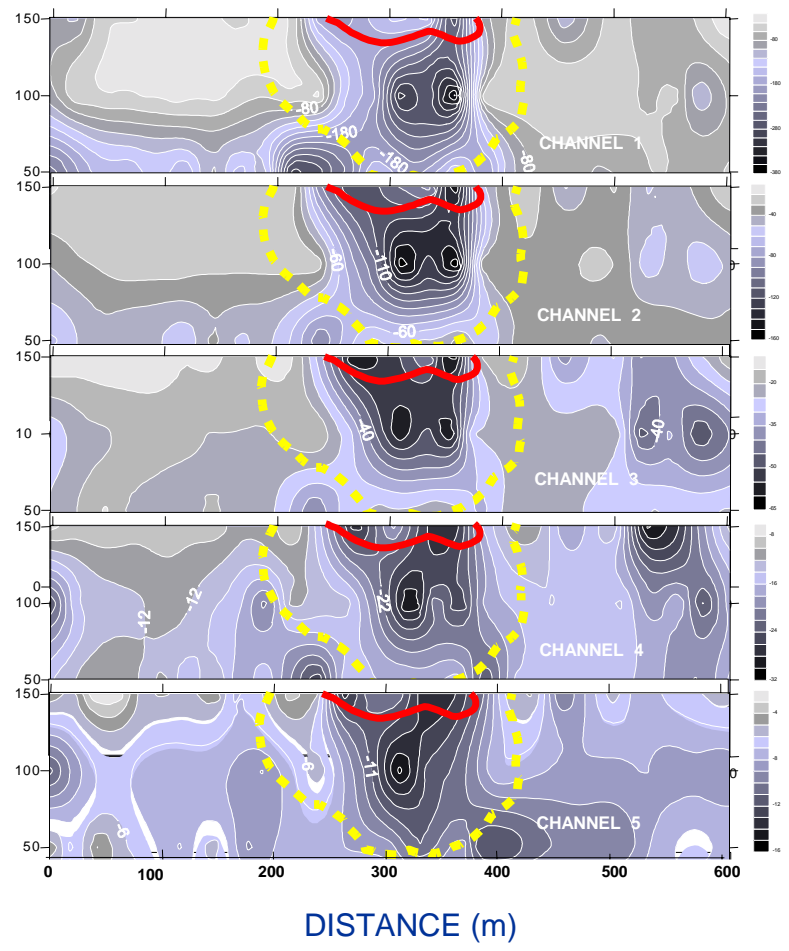

Figure 2b: TDEM response of Pipe 6, Wajrakarur, A.P. 


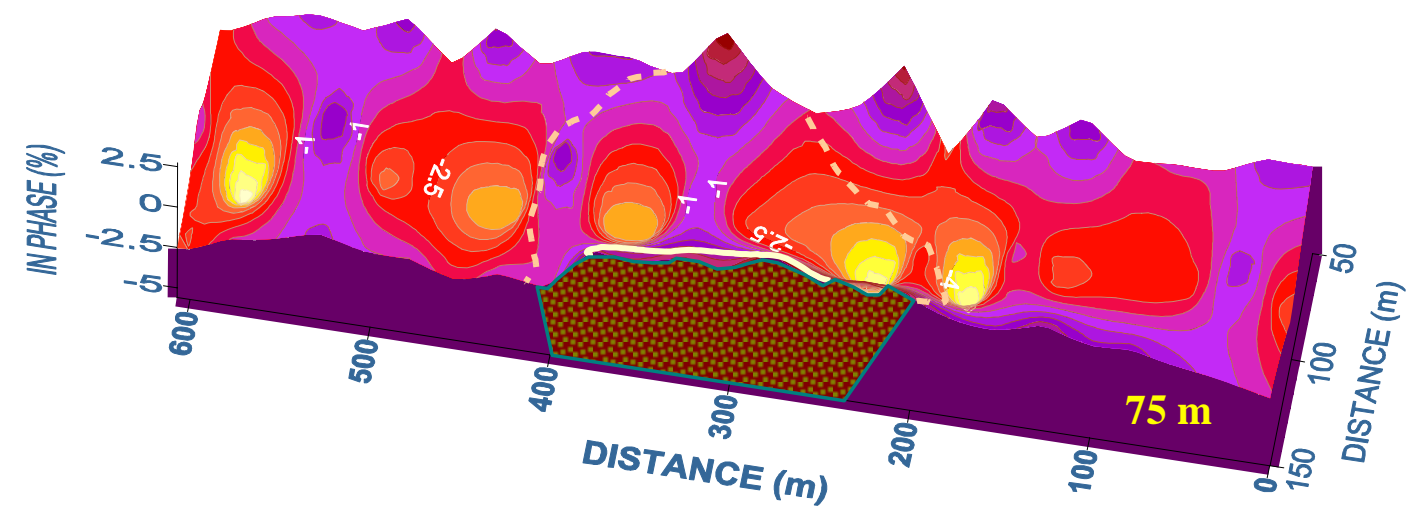

Figure 3a: Image of Pipe 6 obtained by FDEM method for a depth of $75 \mathrm{~m}$.

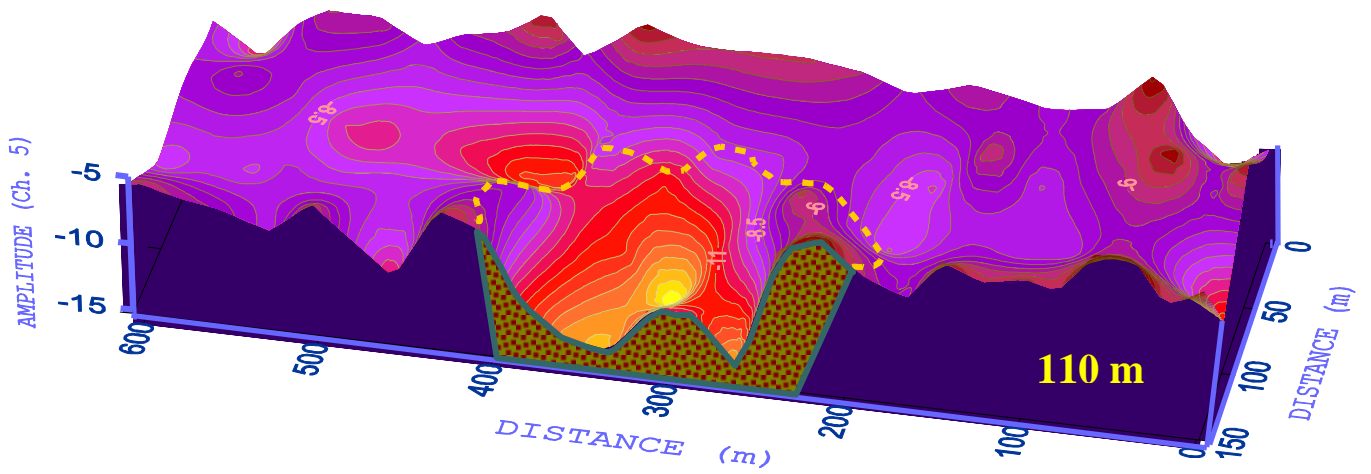

Figure 3b: Image of Pipe 6 obtained by TDEM method for a depth of $110 \mathrm{~m}$.
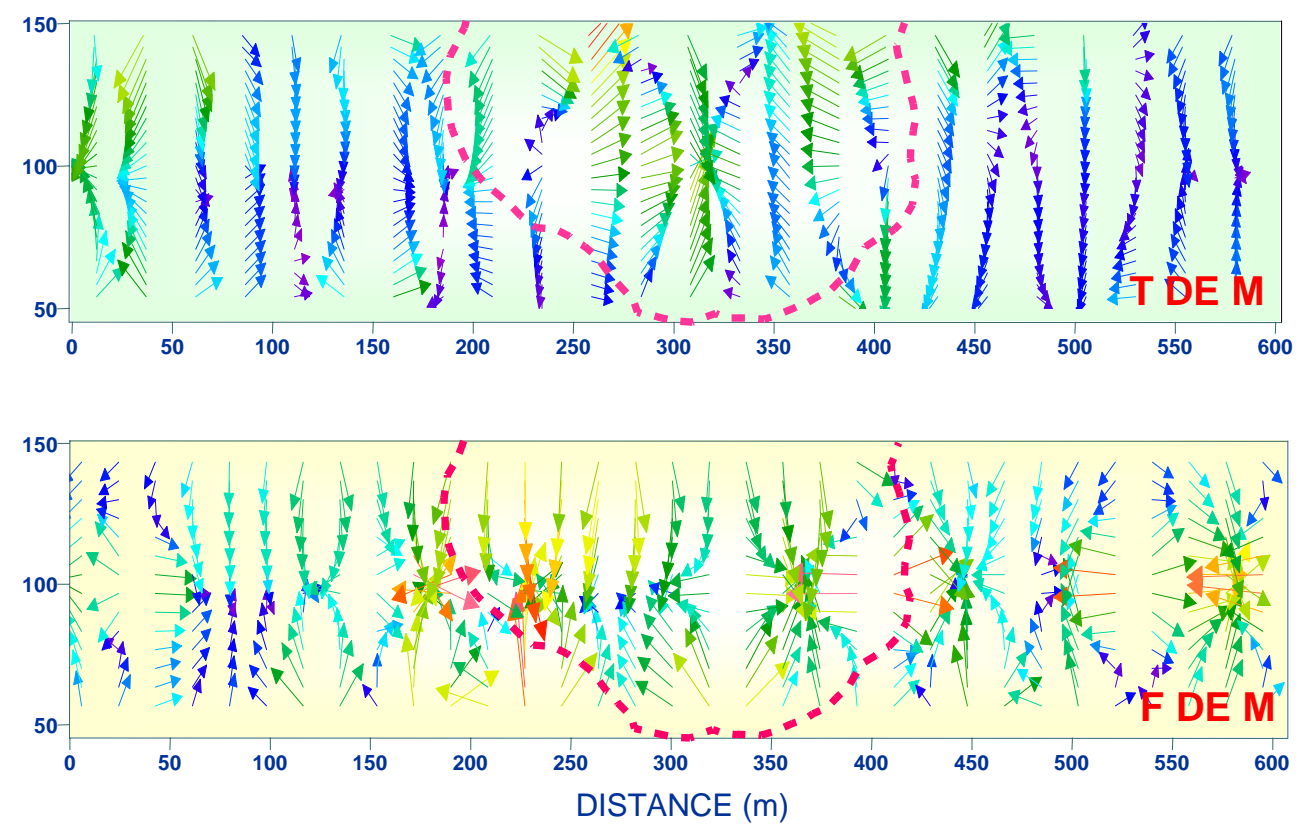

Figure 4: Anomaly vectors plotted for TDEM and FDEM data over Pipe 6 


\section{ADVANTAGE OF SIMULTANEOUS EM \& MAGNETIC SURVEYS}

As already mentioned, the degree of weathering plays an important role in the geophysical response of a $\mathrm{K} / \mathrm{L}$ body. The top region, comprising crater facies, collects water that weathers the uppermost parts of the pipe. Conductive clayey minerals are formed and the region is called 'yellow ground'. Due to weathering, this part also loses its magnetic characteristics significantly. The region immediately below it is called 'blue ground'. It is partially weathered and hence is moderately conducting and somewhat more magnetic than the top part. The un-weathered diatreme facies lies below the blue ground. Due to absence of weathering, it remains hard and compact with no clayey minerals. Thus its electrical resistivity is high. Also, it retains magnetic characteristics to give a good magnetic response. The magnetic part of the pipe starts at a deeper level compared to the conductive zone.

Simultaneous application of electromagnetic and magnetic methods can be particularly useful in identifying weathered kimberlites. In a potential area, magnetic method alone would yield a number of 'bull's eye' anomalies that may be due to a K/L body or due to a variety of other sources. In general it is difficult to correlate them straight away with a $\mathrm{K} / \mathrm{L}$. Also, it is not practical to examine each of them in detail. However, if EM survey indicates conducting localized structures associated with 'bull's eye' magnetic anomalies, chances are fairly good to locate a weathered kimberlite. The possibility is further strengthened if the quantitative analysis reveals that the conducting zone is shallower than the top of magnetic part of the pipe.

\section{REFERENCES}

Guptasarma, D., Chetty, T.R.K., Murthy, D.S.N., Ramana Rao, A.V., Venkatanarayana, B., Babu Rao, V., Shanker Reddy, B., and Singh, Bijendra, 1989. Case history of a kimberlite discovery, Wajrakarur area, AP, south India, In: (Ed. G.D. Garland) Proc. Exploration '87, Ontario Geological Survey, Spl. Vol. 3 , pp 888-897.

Kailasam, L.N., B.G.K. Murty, A.T.S.R. Chayanulu, V.L. Raju, and T.S. Ramachandran, 1978. Regional and detailed gravity and magnetic surveys of kimberlite occurrences and deep structural features in the Wajrakarur and neighbouring areas of Andhra Pradesh, Proc. of the Symp. on 'Exploration Geophysics in India', 1945-1978, GSI Spl. Pub. Series no. 2, 19-33.
Verma, S.K., 2000. Geological and geophysical fabric of Indian cratons in context of diamond exploration. In: Saurabh K. Verma (Ed.) Status Complexities and Challenges of Diamond Exploration in India. Proc. USEFI Workshop, Raipur, India, pp 9-20.

Contact: Saurabh K. Verma, National Geophysical Research Institute, Uppal Road, Hyderabad 500 007, AP, India.

E-mail: skvngri@hotmail.com 